\title{
Efficacy of 5-FU/LV plus CPT-11 as first-line adjuvant chemotherapy for stage IIIa colorectal cancer
}

\author{
MASAYA MUKAI ${ }^{1}$, KAZUTAKE OKADA ${ }^{1}$, HIROSHI FUKUMITSU ${ }^{1}$, NAOKI YAZAWA ${ }^{1}$, \\ TATSUHIKO HOSHIKAWA ${ }^{1}$, TAKAYUKI TAJIMA ${ }^{1}$, HITOSHI HIRAKAWA ${ }^{1}$, \\ KYOUJI OGOSHI $^{2}$ and HIROYASU MAKUUCHI ${ }^{1}$
}

${ }^{1}$ Tokai University Hachioji Hospital, Department of Surgery, Ishikawa-cho 1838, Hachioji, Tokyo 192-0032;
${ }^{2}$ Tokai University School of Medicine, Department of Surgery, Bohseidai, Isehara, Kanagawa 259-1193, Japan

Received May 5, 2009; Accepted June 19, 2009

DOI: $10.3892 /$ or_00000481

\begin{abstract}
The aim of this study was to retrospectively evaluate the effect of adding CPT-11 to postoperative chemotherapy for stage III colorectal cancer. The subjects were 94 patients, including 60 in stage IIIa ( $\leq 3$ positive nodes) and 34 in stage IIIb ( $\geq 4$ positive nodes), who underwent curative resection. The clinical outcome was compared between patients receiving 5-FU/LV plus CPT-11 (FLC group) and patients receiving 5-FU/LV alone (FL group). The FLC group (54 patients) had a 3-year relapse-free survival (3Y-RFS) of $68.7 \%$, a $5 \mathrm{Y}$-RFS of $68.7 \%$ and a $5 \mathrm{Y}-$ OS of $67.1 \%$, while the FL group (40 patients) had a $3 \mathrm{Y}$ RFS of $67.5 \%$ (n.s.), a 5Y-RFS of $64.9 \%$ (n.s.), and a $5 Y-O S$ of $77.3 \%$ (n.s.). There were no significant differences of these parameters between the two groups. For stage IIIa patients, the corresponding survival rates were 92.4, 92.4 and $90.9 \%$ in the FLC group (29 patients) vs. $64.5 \%$ ( $\mathrm{p}=0.024$ ), $61.1 \%(\mathrm{p}=0.018)$, and $77.1 \%$ (n.s.) in the FL group (31 patients). For stage IIIb patients, the rates were 36.6, 36.6 and $24.8 \%$ in the FLC group (25 patients) vs. $77.8 \%$ (n.s.), $77.8 \%$ (n.s.), and $77.8 \%$ (n.s.) in the FL group (9 patients). These results suggest that the 3 Y-RFS and 5Y-RFS of patients with stage IIIa colorectal cancer were significantly improved by adjuvant chemotherapy with 5 -FU/LV plus CPT-11.
\end{abstract}

Correspondence to: Dr Masaya Mukai, Tokai University Hachioji Hospital, Department of Surgery, Ishikawa-cho 1838, Hachioji, Tokyo 192-0032, Japan

E-mail:mukai.masaya@hachioji-hosp.tokai.ac.jp

Abbreviations: 5-FU, 5-fluorouracil; LV, leucovorin; CPT-11, irinotecan; L-OHP, oxaliplatin; UFT, tegafur/uracil; PSK, krestin; TS, thymidilate synthase; DPD, dihydropyrimidine dehydrogenase; 3Y-RFS, 3-year relapse-free survival; 5Y-RFS, 5-year relapse-free survival; 5Y-OS, 5-year overall survival; ONCs, occult neoplastic cells; LN, lymph node; ITCs, isolated tumor cells

Key words: colorectal cancer, adjuvant chemotherapy, 5-FU/LV, CPT-11, UFT, PSK, occult neoplastic cells

\section{Introduction}

In Japan, the prognosis of colorectal cancer has recently shown a marked improvement with the development of adjuvant therapies such as chemotherapy and radiotherapy, as well as better surgical treatment. A 5-year survival rate of approximately $80-85 \%$ (colon: $84.5 \pm 2.8 \%$; rectum: $79.8 \pm 4.0 \%$ ) has been reported for patients with stage II/ Dukes' B cancer, which is not accompanied by any nodal metastasis, after curative resection (1-3). In patients with stage III/Dukes' C cancer who have nodal metastases, the 5-year survival rate falls to $60-70 \%$ (colon: $74.0 \pm 3.5 \%$; rectum: $64.7 \pm 4.3 \%$ ) despite curative resection, so $30-40 \%$ of these patients have distant metastasis/recurrence that life threatens their survival (1-3). According to the TNM classification, patients with lymph node involvement are further classified into two groups according to the number of metastases: $\mathrm{N} 1$ ( $\leq 3$ positive nodes)/stage IIIA or IIIB, and $\mathrm{N} 2$ ( $\geq 4$ positive nodes)/stage IIIC (this status is unrelated to the $\mathrm{T}$ category) (4). The Japanese 'General Rules for Clinical and Pathological Studies on Cancer of the Colon, Rectum, and Anus' were revised in 2007 (7th edition) to classify patients as follows: stage IIIa/N1 ( $\leq 3$ positive nodes), or stage IIIb/N2 ( $\geq 4$ positive nodes $=$ TNM stage IIIC) (5). Breast cancer is generally accompanied by lymph node involvement, and thus is considered to be a systemic disease. Its subclassification is also performed according to the number of nodal metastases. Thus, the number of lymph node metastases is an important factor that determines the prognosis of various cancers (6-8).

Fatal hematogenous distant metastasis/recurrence in the liver or lungs of patients with stage II/III colorectal cancer may occur after curative resection if cancer cells that circulate in the blood during the perioperative period escape the host's immunological defenses and find a favorable microenvironment in the liver or lungs that allows subsequent proliferation (9). Accordingly, the importance of postoperative adjuvant chemotherapy presumably lies in achieving the eradication of residual free cancer cells, which circulate around the body in the perioperative period (10-12). In Europe and the United States, multidrug regimens have come into common use as adjuvant chemotherapy for patients who have stage III colorectal cancer with nodal metastases. Among 


\title{
FLC group; 5-FU/LV + CPT-11
}

\section{5 consecutive days (1-5) per week + Day 15 / month / 1 course}

\author{
$\sqrt{20000}$ \\ Day $1-5-15-28 / 1$ course $x$ 5-6 months, and UFT+PSK 6 months or more* \\ a 5 -FU $\quad 350 \mathrm{mg} / \mathrm{m}^{2}+\mathrm{LV} 150 \mathrm{mg} / \mathrm{m}^{2}$ (5 consecutive infusions / month) \\ V CPT-11 $60 \mathrm{mg} / \mathrm{m}^{2}$ (bi-weekly infusions / month) \\ * UFT $400 \mathrm{mg} / \mathrm{m}^{2}+$ PSK $3.0 \mathrm{~g} / \mathrm{body}$; \\ 5 consecutive days (1-5) on/weekends off per week/ month / 1 course \\ x 6 months or more
}

\section{FL group; 5-FU/LV}

5 consecutive days (1-5) per week / month / 1 course

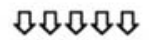 \\ Day 1 - 5 - 28 / 1 course $x$ 5-6 months, and UFT+PSK 6 months or more* \\ s $5-\mathrm{FU} 350 \mathrm{mg} / \mathrm{m}^{2}+\mathrm{LV} 150 \mathrm{mg} / \mathrm{m}^{2}$ (5 consecutive infusions / month) \\ * UFT $400 \mathrm{mg} / \mathrm{m}^{2}+$ PSK 3.0g/body; \\ 5 consecutive days (1-5) on/weekends off per week / month / 1 course \\ $x 6$ months or more
}

Figure 1. The FL group received the modified Machover regimen [5-FU $\left(350 \mathrm{mg} / \mathrm{m}^{2}\right)+\mathrm{LV}\left(150 \mathrm{mg} / \mathrm{m}^{2}\right): 5$ consecutive days every month x 5-6 courses] of high-dose 5-FU plus high-dose LV for 5 consecutive days monthly, followed by oral UFT ( $\left.400 \mathrm{mg} / \mathrm{m}^{2}\right)$ plus PSK ( $\left.3.0 \mathrm{~g}\right)$ on 5 consecutive days weekly for 6 months or more. The FLC group received the modified Machover regimen plus CPT-11 (60 mg/m² on days 1 and 15 every month x 5-6 courses), followed by the same oral UFT plus PSK regimen for 6 months or more as the FL group.

such treatments are the IFL/FOLFIRI/FOLFOX regimens that employ the topoisomerase-1 inhibitor irinotecan (CPT-11) and/or the new generation platinum derivative oxaliplatin (L-OHP), which differ markedly from 5-fluorouracil (5-FU)/ leucovorin $(\mathrm{LV})$ therapy in a combination of 5-FU and LV to stimulate the metabolism of 5-FU, with respect to their mechanism of action (13-16). The Japanese treatment guidelines recommend 5-FU/LV therapy as the first-line standard adjuvant chemotherapy for patients with stage III colorectal cancer. When recurrence occurs following such therapy, however, the possibility that the relevant drugs do not have sufficient activity has been reported, because not many patients have tumors that are highly susceptible to 5-FU/LV therapy according to investigations into the levels of thymidilate synthase (TS; an enzyme involved in 5-FU metabolism) and dihydropyrimidine dehydrogenase (DPD; a 5-FU degrading enzyme) in tumor tissue specimens (10-12). Although the dosage and administration regimen also have an important influence on the activity of drugs, the most important factor is tumor sensitivity and the activity of any additional drugs. In this context, multidrug combination therapy using CPT-11 and L-OHP (e.g., IFL, FOLFIRI or FOLFOX), which is more commonly employed in Europe and the United States than in Japan, has been reported to be more effective than 5-FU/LV therapy (13-16).

In Japan, however, no studies have been done concerning the efficacy of postoperative adjuvant chemotherapy with 5-FU/LV plus CPT-11 compared with the standard regimen of 5-FU/LV in patients with node-positive stage III colorectal cancer classified according to the number of metastases as in the TNM classification who have undergone curative resection. Accordingly, the objective of the present study was to evaluate the efficacy of adding CPT-11 to adjuvant chemotherapy for stage III colorectal cancer by comparing $5-\mathrm{FU} / \mathrm{LV}+\mathrm{CPT}-11$ with $5-\mathrm{FU} / \mathrm{LV}$ in patients stratified by the number of positive nodes.

\section{Patients and methods}

Among patients with primary colorectal cancer undergoing curative resection during the period of approximately nine years from January 2000 to December 2008, 112 fulfilled the following conditions: i) an age of 75 years or younger, ii) a performance status of 0 or 1 , iii) complete medical records that made it possible to determine the presence or absence of tumor recurrence/metastasis and the survival status, iv) data about the number of lymph node metastases and v) pathological stage III. Of these 112 patients, 94 who received five to six courses of treatment after surgery were entered into this study. The FL group $(n=40)$ received the modified Machover regimen [5-FU $\left(350 \mathrm{mg} / \mathrm{m}^{2}\right)+\mathrm{LV}\left(150 \mathrm{mg} / \mathrm{m}^{2}\right)$ on 5 consecutive days every month x 5-6 courses], which involved high-dose 5-FU plus high-dose LV for 5 consecutive days monthly, followed by oral UFT $\left(400 \mathrm{mg} / \mathrm{m}^{2}\right)$ plus PSK $(3.0 \mathrm{~g})$ on 5 consecutive days weekly for at least 6 months (Fig. 1) (17-19). The FLC group ( $n=54)$ received the modified Machover regimen plus intravenous CPT-11 [(60 mg/m²) on days 1 and 15 every month x 5-6 courses], followed by the same oral UFT plus PSK therapy for 6 months or more as the FL group (Fig. 1) $(17,19,20)$.

Patient eligibility was determined as follows. The medical records of Stage III patients were reviewed and those who had received 5-6 complete courses of parenteral treatment after surgery were entered into the study. The total number of 


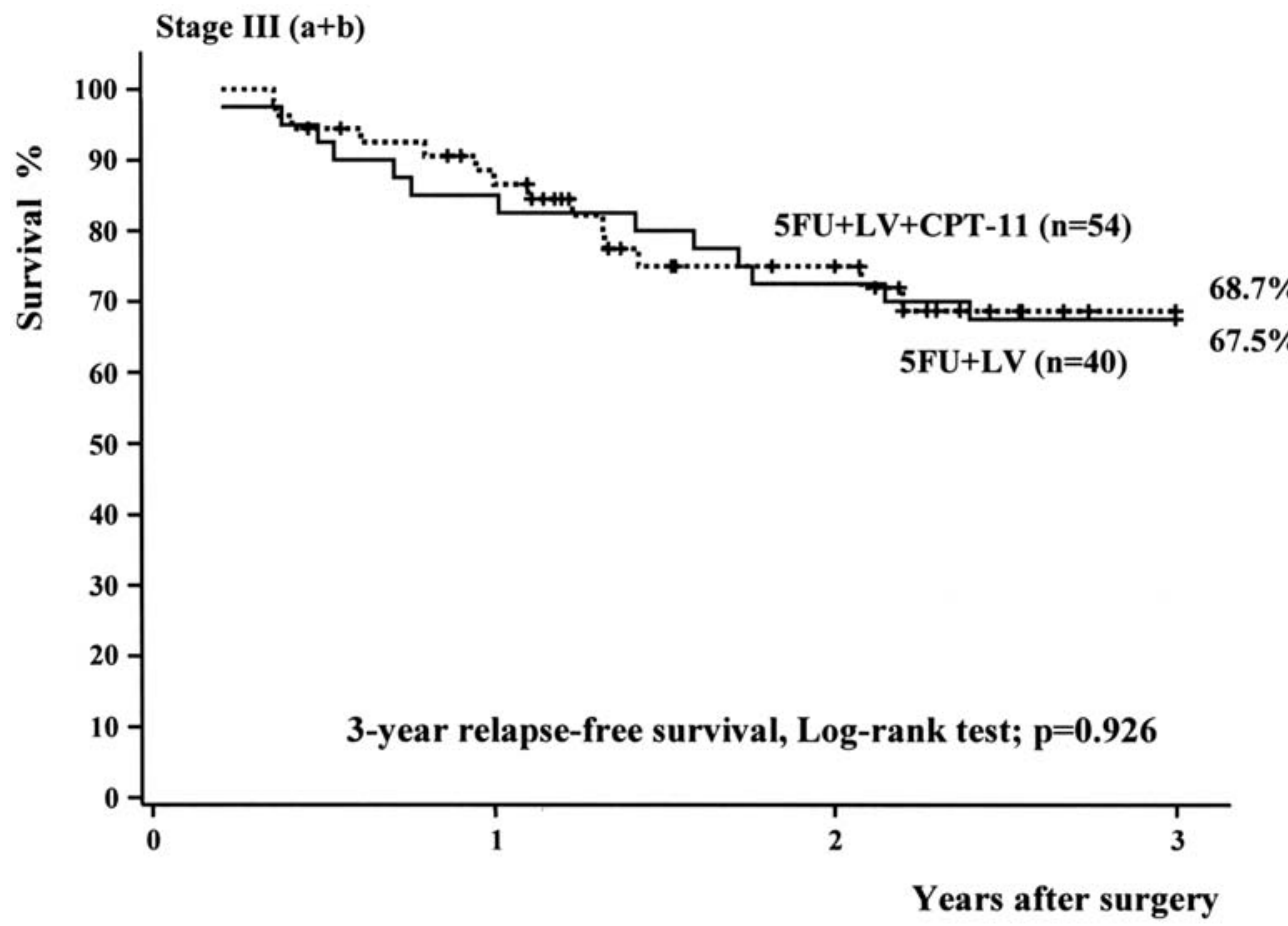

Figure 2. Among all stage III patients (IIIa+IIIb), 3Y-RFS was $68.7 \%$ for the FLC group (54 patients) and $67.5 \%$ for the FL group (40 patients), showing no significant difference $(\mathrm{p}=0.926)$.

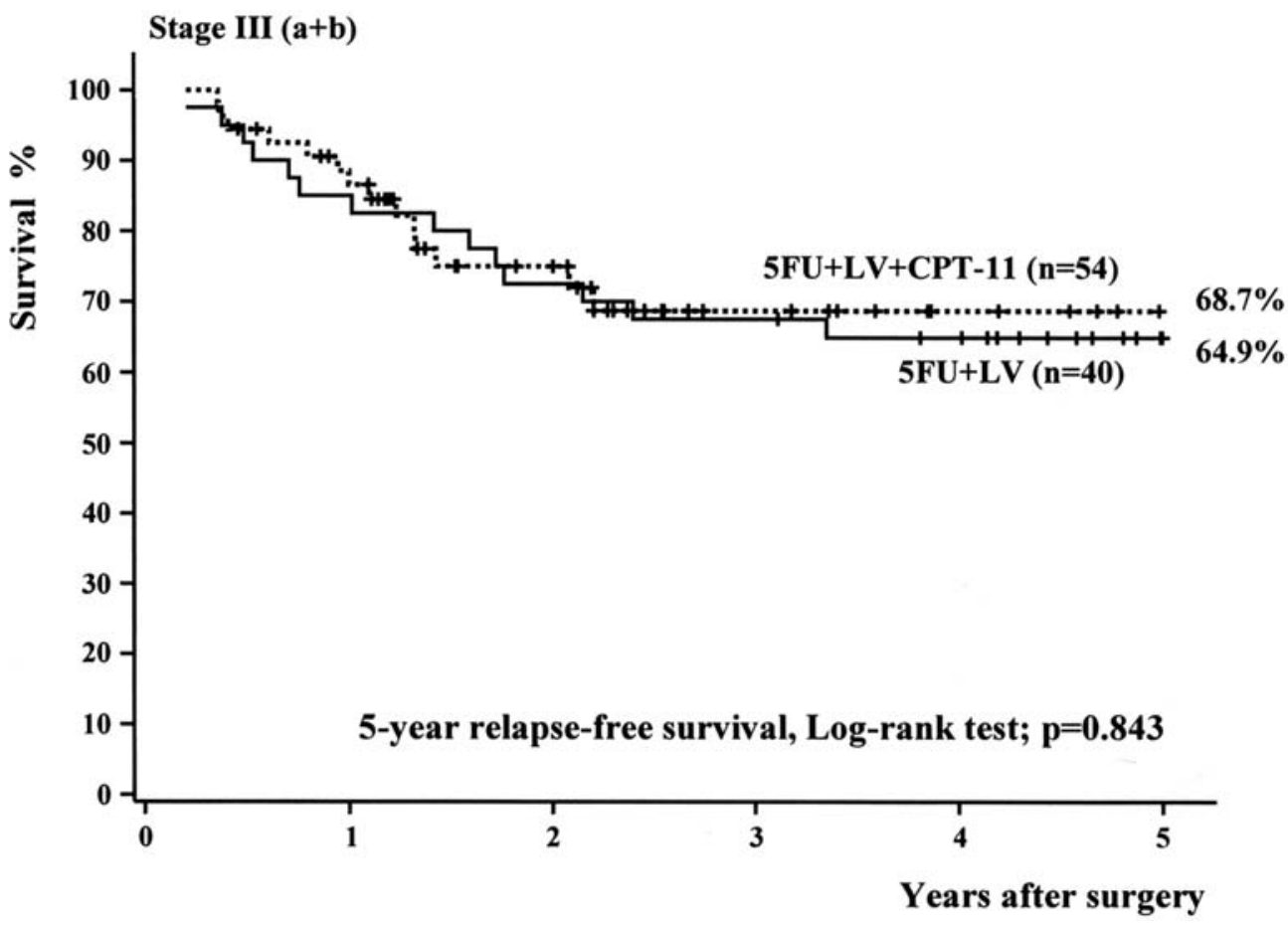

Figure 3. Among all stage III patients (IIIa+IIIb), 5Y-RFS was $68.7 \%$ for the FLC group (54 patients) and 64.9\% for the FL group (40 patients), showing no significant difference $(\mathrm{p}=0.843)$.

chemotherapy courses and the mean number of courses were calculated. To assess oral treatment compliance, the medical records were checked and the results of a questionnaire on compliance were reviewed. Patients in whom treatment was suspended for less than one month and who were ascertained to have shown compliance for 6 months or more were also eligible as subjects $(18,19)$. To detect metastasis/recurrence, patients were examined every three months from 3 months after surgery and clinical relapse was considered to have occurred when US or CT scanning revealed a metastatic lesion. The subjects were classified into three categories, which were stage III, stage IIIa (stage IIIA or B according to the TNM classification; $\leq 3$ positive nodes); and stage IIIb (stage IIIC according to the TNM classification; $\geq 4$ positive 


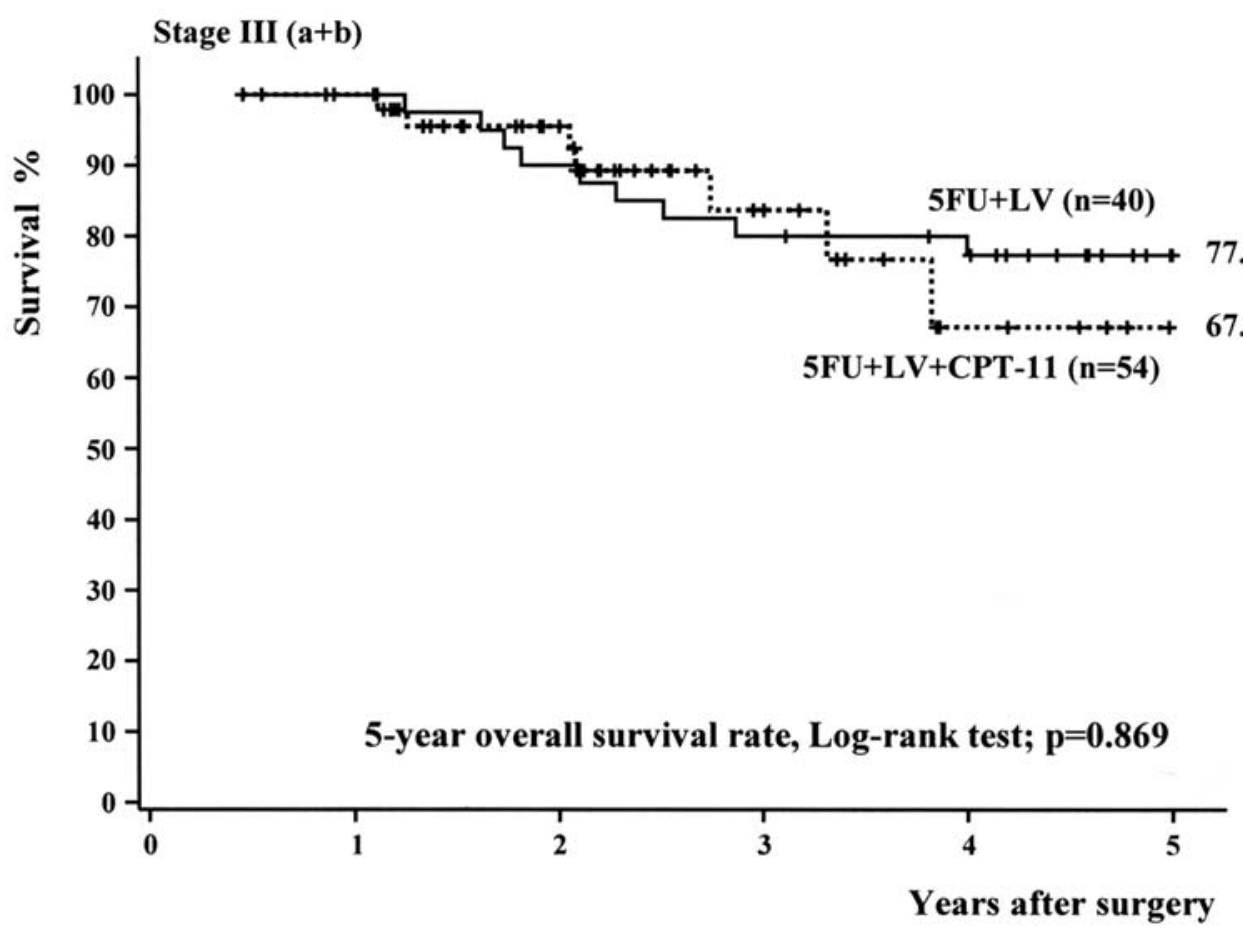

Figure 4. Among all stage III patients (IIIa+IIIb), 5Y-OS was $67.1 \%$ for the FLC group (54 patients) and $77.3 \%$ for the FL group (40 patients), showing no significant difference $(\mathrm{p}=0.869)$.

nodes). The FLC and FL groups were compared by calculation of the 3-year relapse-free survival rate (3Y-RFS), 5-year relapse-free survival rate (5Y-RFS), and 5-year overall survival rate $(5 \mathrm{Y}-\mathrm{OS})$

Statistical analysis. To calculate the 3-year relapse-free survival rate, 5-year relapse-free survival rate and 5-year overall survival rate, the Kaplan-Meier method was used, and the log-rank test was employed for comparisons between groups. A $\mathrm{P}<0.05$ was considered to indicate a significant difference. All analyses were done with SPSS $16.0 \mathrm{~J}$ software (SPSS Japan, Inc., Tokyo, Japan).

\section{Results}

The 54 patients in the FLC group received a total of 315 courses of treatment (a mean of 5.8 courses per patient), whereas the 40 patients in the FL group received a total 235 courses (a mean of 5.9 courses per patient). When all stage III patients (IIIa+IIIb) were combined, the FLC group had a 3 Y-RFS of $68.7 \%$ (Fig. 2), a 5 Y-RFS of $68.7 \%$ (Fig. 3), and a 5Y-OS of $67.1 \%$ (Fig. 4), whereas the FL group had a $3 \mathrm{Y}$-RFS of $67.5 \%$ ( $\mathrm{p}=0.926)$ (Fig. 2), a 5Y-RFS of $64.9 \%(\mathrm{p}=0.843)$ (Fig. 3), and a 5Y-OS of $77.3 \%(\mathrm{p}=0.869)$ (Fig. 4). There were no significant differences of any parameters between the two groups. Among the 60 stage IIIa patients, the FLC group (29 patients) showed a 3Y-RFS of $92.4 \%$ (Fig. 5), a $5 Y-R F S$ of $92.4 \%$ (Fig. 6), and a 5 Y-OS of $90.9 \%$ (Fig. 7), while the corresponding values for the FL group (31 patients) were $64.5 \%(\mathrm{p}=0.024)$ (Fig. 5), 61.1\% ( $\mathrm{p}=0.018)$ (Fig. 6), and $77.1 \%$ ( $\mathrm{p}=0.171$ ) (Fig. 7). The corresponding values for the 34 stage IIIb patients were $36.6 \%$ (Fig. 8), 36.6\% (Fig. 9), and $24.8 \%$ (Fig. 10) in the FLC group (25 patients) vs. $77.8 \%$ $(\mathrm{p}=0.119)$ (Fig. 8), 77.8\% (p=0.119) (Fig. 9), and 77.8\% $(\mathrm{p}=0.124)$ (Fig. 10) in the FL group (9 patients).

\section{Discussion}

The Japanese treatment guidelines recommend intravenous administration of 5-FU and LV as first-line postoperative adjuvant therapy for patients with stage III colorectal cancer, but the dosage and administration details are not specified $(2,3)$. With regard to 5-FU/LV therapy, the RPMI regimen (5-FU bolus weekly in combination with a 2-h infusion of LV every 6 weeks followed by a 2-week rest every 8 weeks x 3 courses over 24 weeks) is widely used in Japan (21). This American regimen has contributed considerably to improvement of QOL because of less frequent outpatient visits than with other regimens. From the viewpoint of the pharmacokinetics of 5-FU, however, it has been pointed out that inhibition of RNA synthesis is achieved due to rapid saturation of the blood level, but it is difficult to induce DNA synthesis inhibition due to variations of the cell cycle (22-25). In fact, 24-h continuous infusion of 5-FU is ideal for achieving maximum inhibition of DNA synthesis, which is the basis of anticancer drug treatment. Other methods (e.g., the de Gramont regimen) cause frequent adverse events such as the hand-foot syndrome or mucositis/oral ulceration, and are based on inpatient treatment that interferes with patient QOL (26). Therefore, we have recommended 5-FU/LV based on Machover's European regimen (5-FU/LV for five consecutive days weekly every month) as an outpatient treatment that achieves comparatively long exposure to 5-FU (17-19). According to some reports, addition of CPT-11 or L-OHP to 5-FU/LV therapy has nearly equivalent of anticancer drug sensitivity. In the first-line setting following curative resection, 


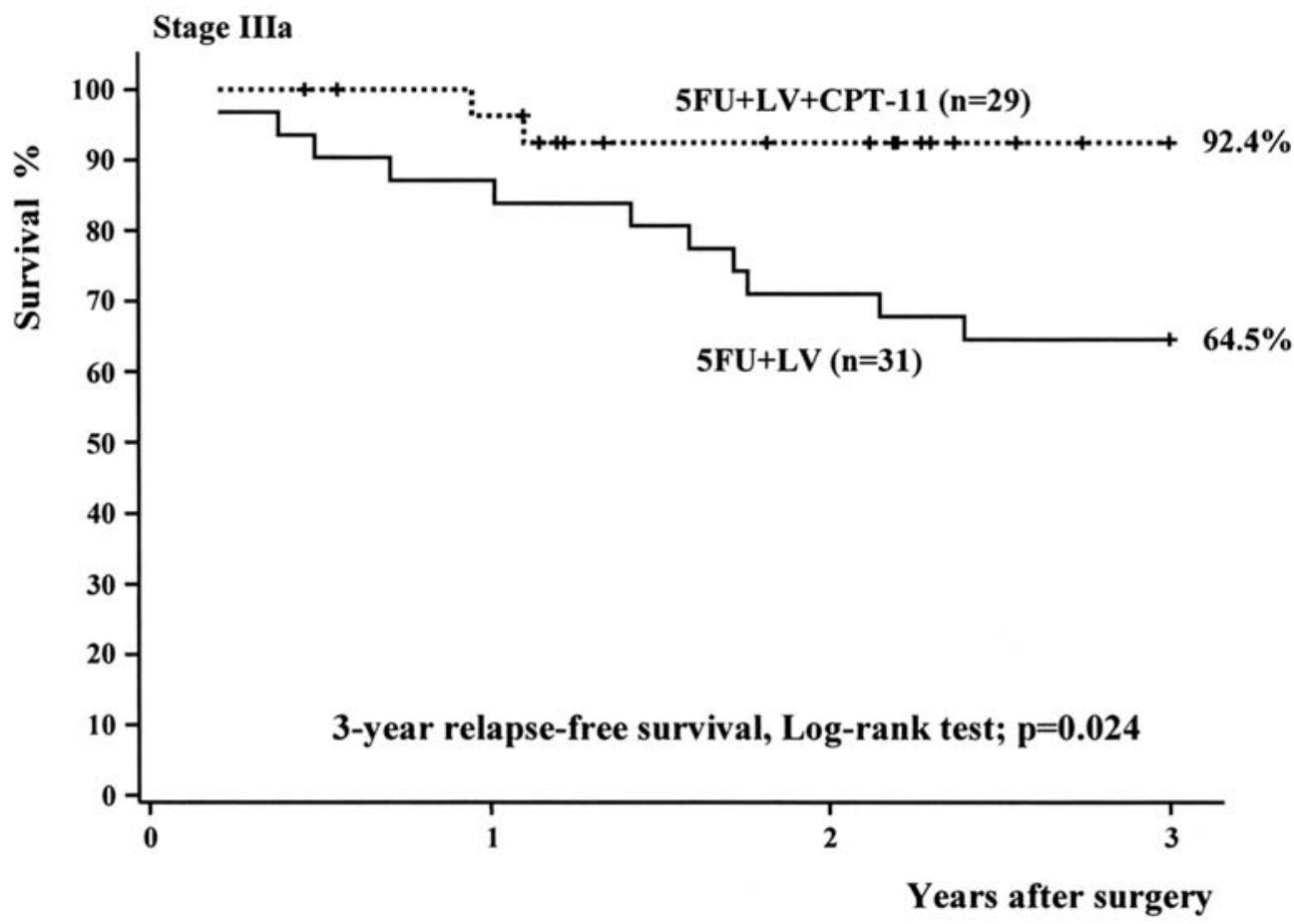

Figure 5. Among stage IIIa patients, 3Y-RFS was $92.4 \%$ for the FLC group (29 patients) and $64.5 \%$ for the FL group (31 patients), showing a significant difference $(\mathrm{p}=0.024)$.

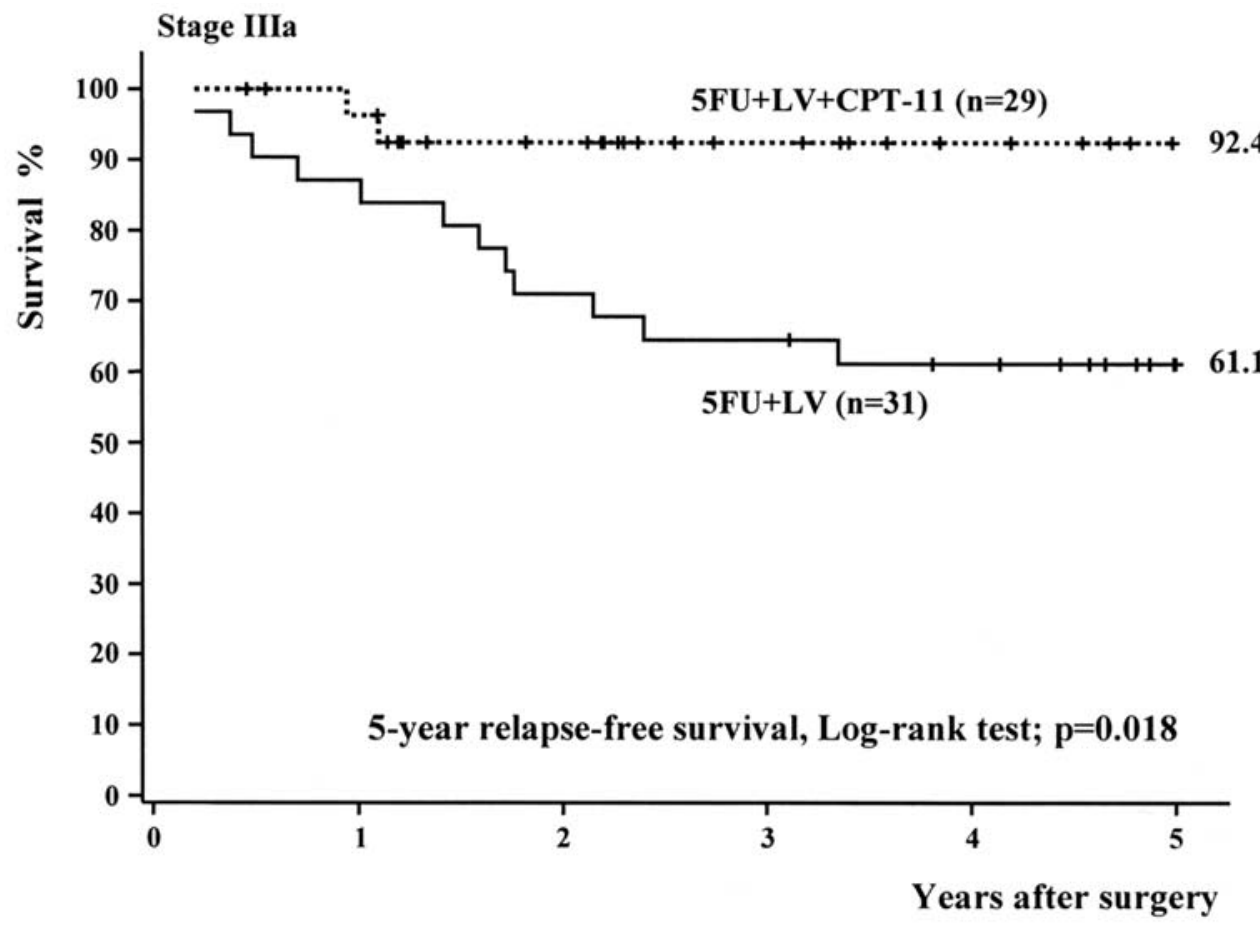

Figure 6. Among stage IIIa patients, 5 Y-RFS was $92.4 \%$ for the FLC group (29 patients) and $61.1 \%$ for the FL group (31 patients), showing a significant difference $(\mathrm{p}=0.018)$.

CPT-11 is a more reasonable choice than L-OHP because of a low incidence of neurological adverse events such as neuropathy and paresthesia and because it is less costly $(11,12,20)$. It would seem advisable to retain L-OHP as a second-line treatment for distant metastasis/recurrence. Based on these considerations, we have used FLC as our standard method of postoperative adjuvant chemotherapy.
The results of the present study showed that the total number of drop-outs or patients receiving $\leq 4$ courses of treatment was small with both regimens (6 in the FLC group and 3 in the FL group). This is chiefly because the dosage of CPT-11 was set at $60 \mathrm{mg} / \mathrm{m}^{2}$, which is lower than the recommended dose of $100 \mathrm{mg} / \mathrm{m}^{2}$ for Europeans and Americans, in order to reduce early drop-outs due to bone marrow 


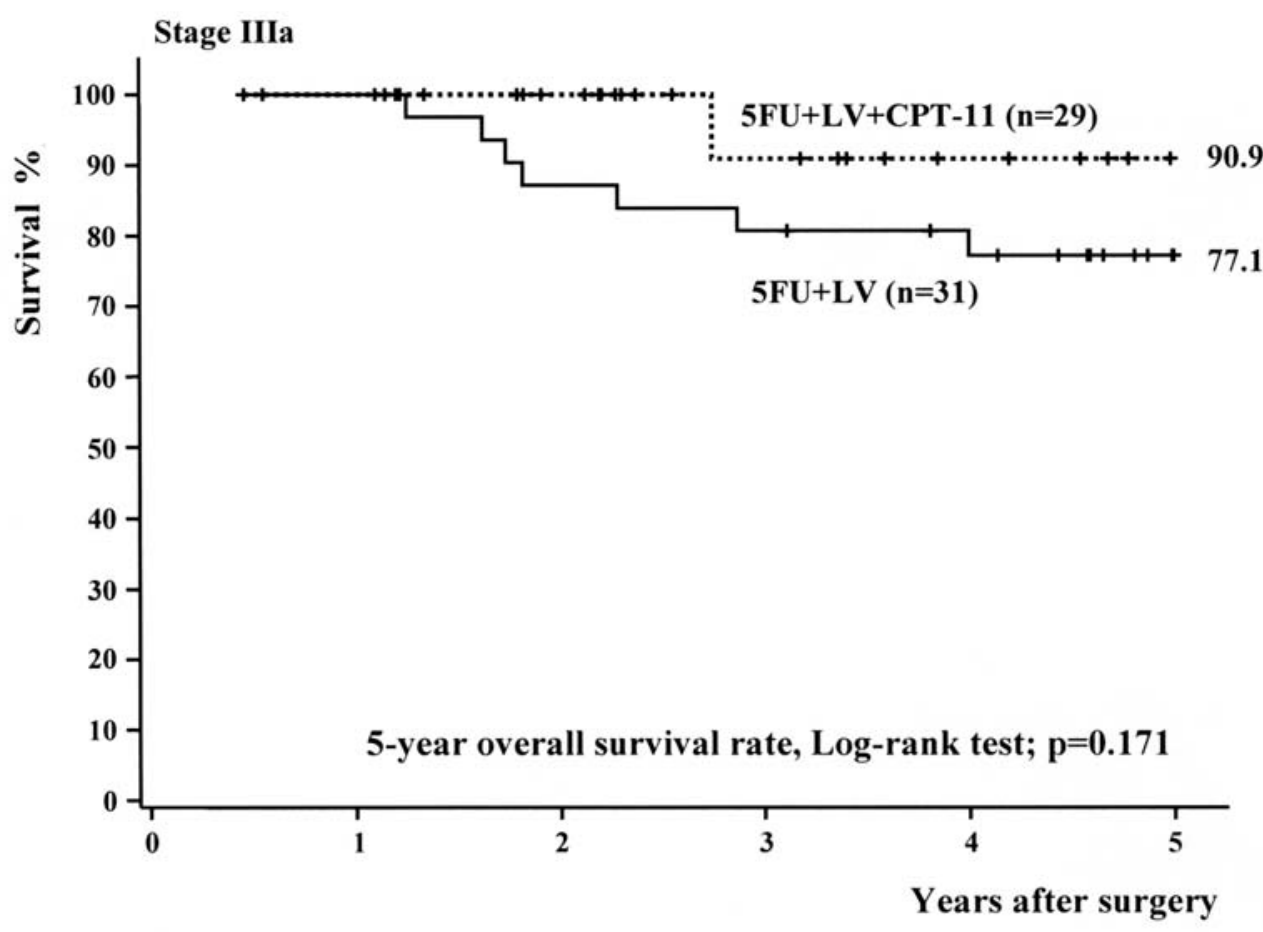

Figure 7. Among stage IIIa patients, 5 Y-OS was $90.9 \%$ for the FLC group (29 patients) and $77.1 \%$ for the FL group (31 patients), showing no significant difference $(\mathrm{p}=0.171)$.

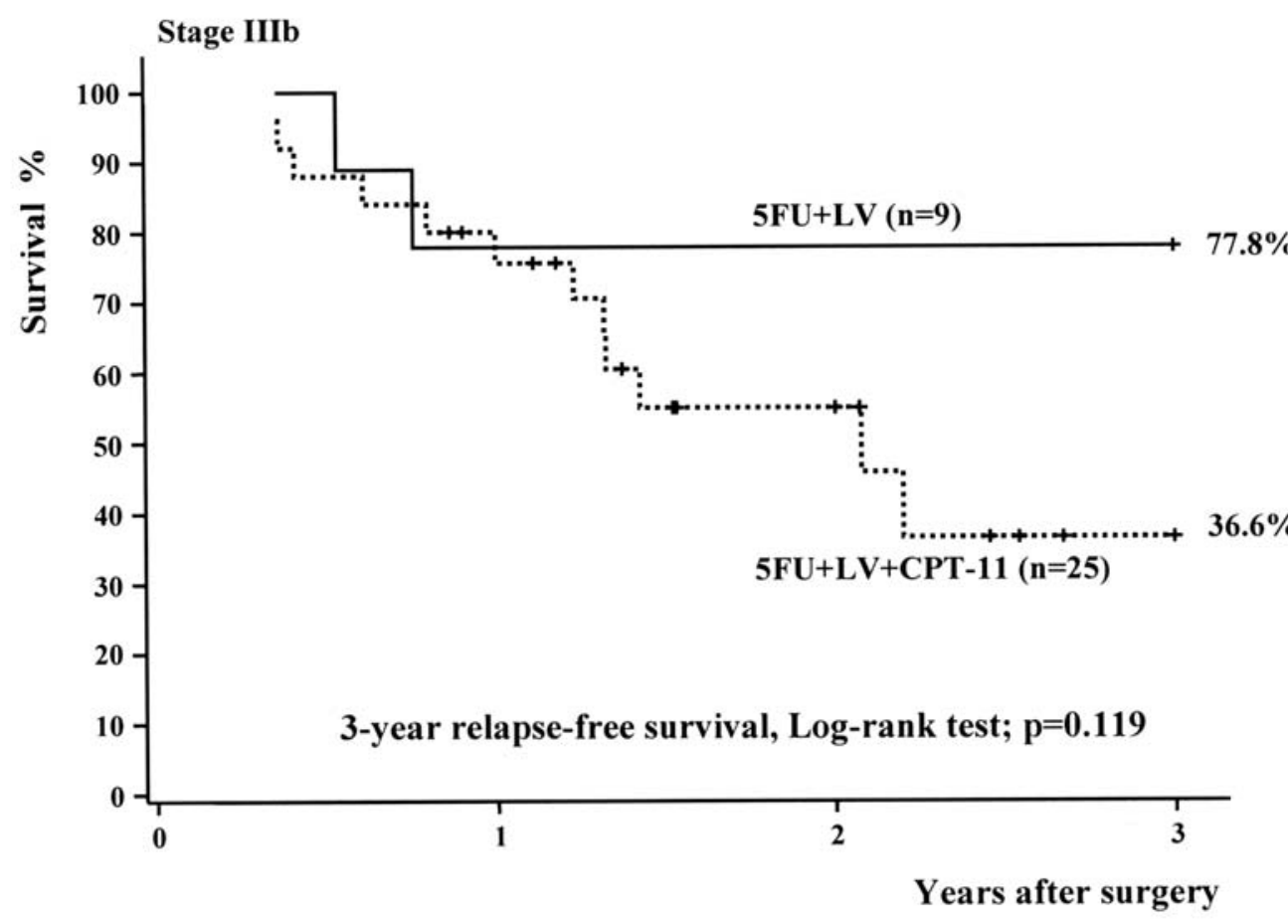

Figure 8. Among stage IIIb patients, 3Y-RFS was $36.6 \%$ for the FLC group (25 patients) and $77.8 \%$ for the FL group (9 patients), showing no significant difference $(\mathrm{p}=0.119)$.

suppression, diarrhea, or other gastrointestinal adverse reactions. Even with this regimen, however, the cumulative dosage exceeds $1,200 \mathrm{mg}$ if a total of six courses are completed. With this regimen there were no serious adverse events (e.g., leucopenia or anemia) of grade 3 or 4 and the reported events were all grade 1 or 2 , including mild leucopenia (approximately 42\%), nausea/vomiting (approximately 50\%), and neuropathy (abnormal sense of smell in approximately $25 \%)(20)$. The FLC regimen allows long-term treatment at moderate doses and is less likely to raise the problem of drop-outs due to adverse events. However, it still blocks DNA synthesis and achieves marked improvement of relapse-free survival in patients with stage IIIa cancer. This finding indicates that the FLC regimen is an optimal modified version 


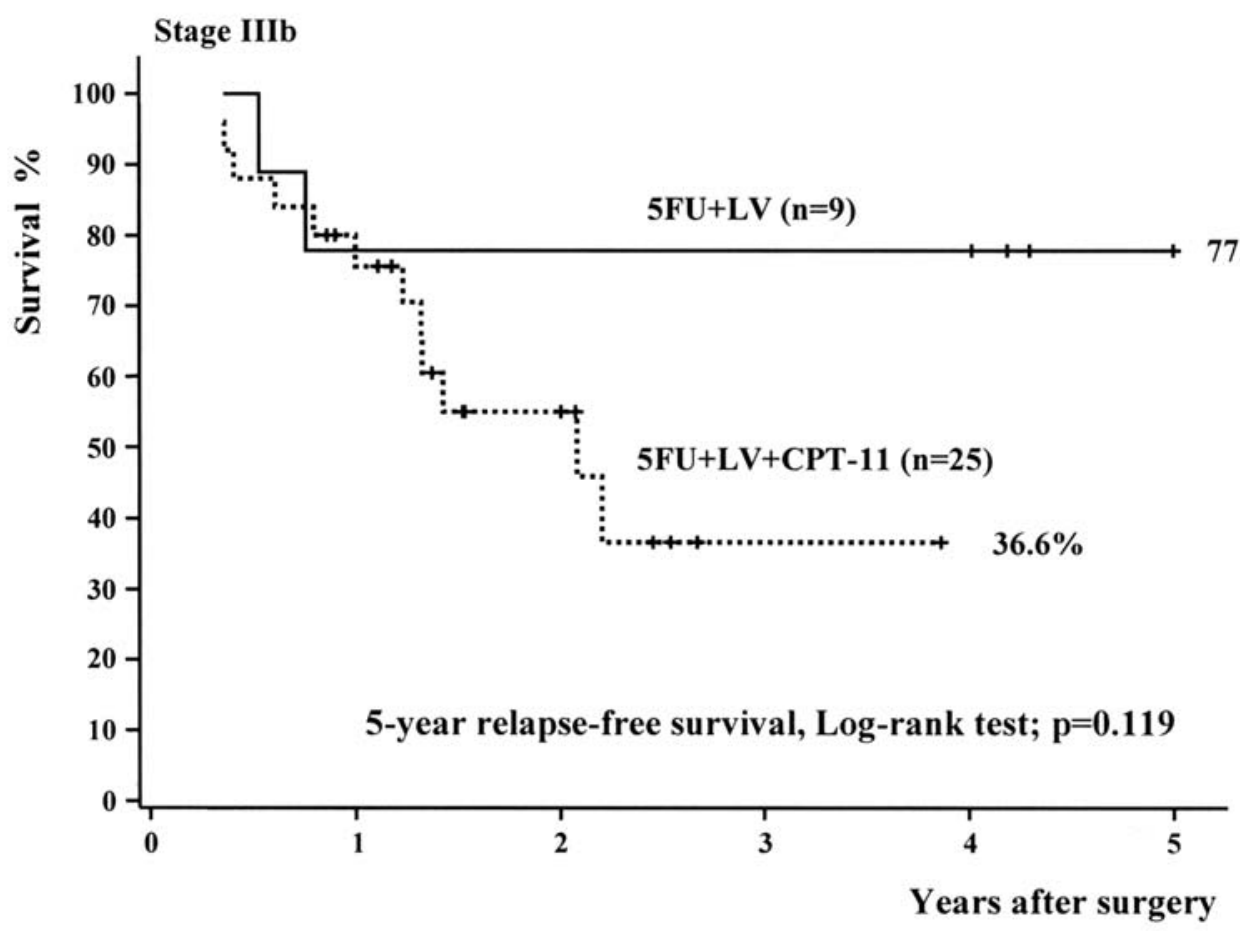

Figure 9. Among stage IIIb patients, 5Y-RFS was 36.6\% for the FLC group (25 patients) and $77.8 \%$ for the FL group (9 patients), showing no significant difference ( $\mathrm{p}=0.119)$.

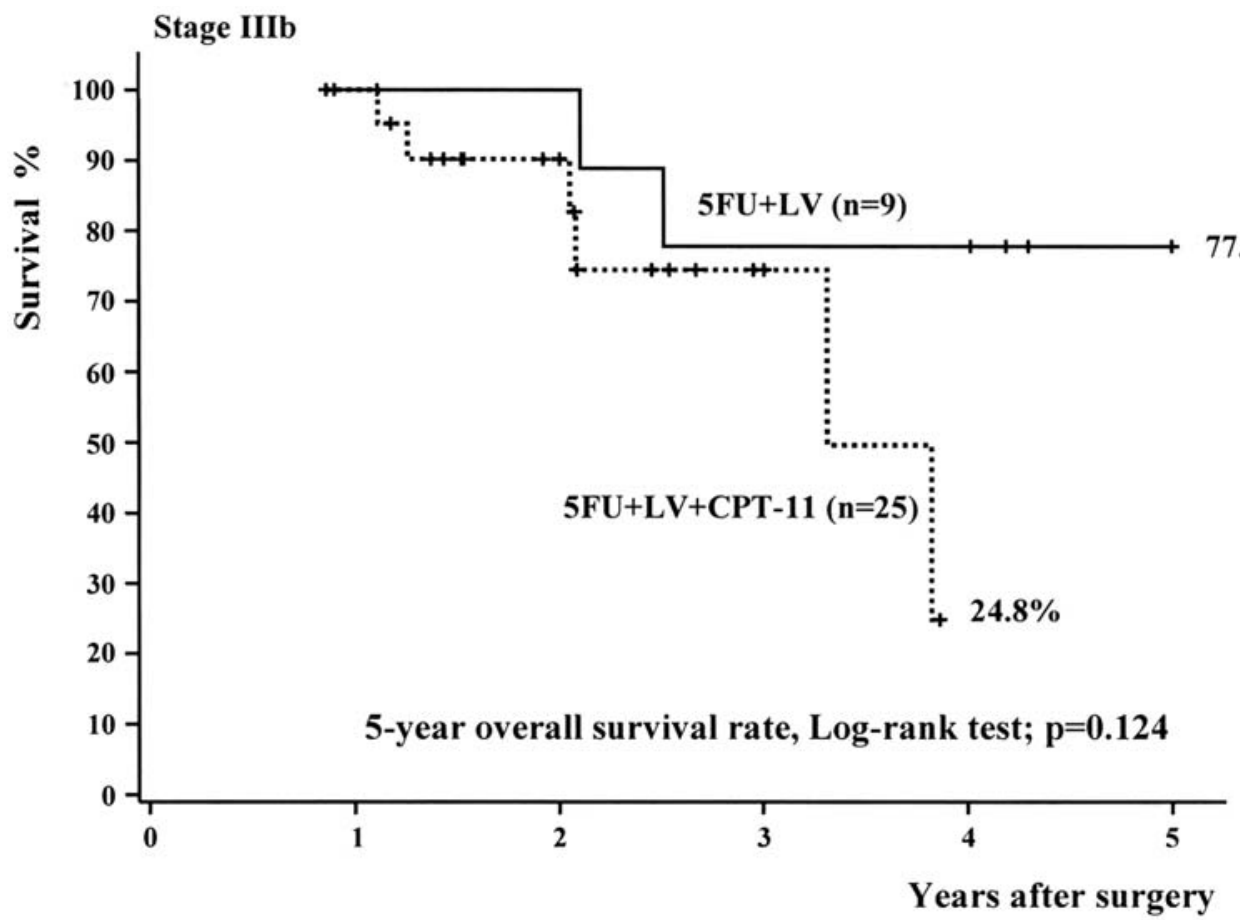

Figure 10. Among stage IIIb patients, 5Y-OS was $77.8 \%$ for the FLC group (25 patients) and $24.8 \%$ for the FL group (9 patients), showing no significant difference $(\mathrm{p}=0.124)$.

of the European and American regimens prepared in consideration of the safe dosage and schedule for Japanese patients with a relatively small body habitus. In the future, it may be worthwhile to suggest options for individual patients with respect to the treatment schedule based on lifestyle and QOL considerations, such as the European regimen
( 5 consecutive days for 1 week every month x 6 courses) or the American regimen (weekly for 6 weeks every 24 weeks).

The results of the present study did not show any additive effect of CPT-11 on tumor control with respect to 3Y-RFS, 5Y-RFS, or 5Y-OS in the overall analysis. Among stage IIIa patients, however, the FLC group had significantly better 
results than the FL group with respect to $3 \mathrm{Y}$-RFS and $5 \mathrm{Y}$ RFS. With regard to the analysis of 5Y-OS, it is very difficult to standardize institutional criteria for resection/non-resection of distant metastasis/recurrence in the liver, lungs, and other organs. In addition, post-recurrence second-line or subsequent therapy, including hepatic arterial infusion, radiofrequency ablation (RFA), and XRT, has not been standardized. This suggests that, under the present circumstances, 3Y-RFS and $5 Y-R F S$ evaluate the control of early recurrence, better than 5Y-OS when assessing approximately 6 months of first-line adjuvant chemotherapy early in the postoperative course, although 5Y-OS is suitable for comparison among institutions (18-20). Colorectal cancer recurs in $60-70 \%$ of patients within approximately 2 years after surgery and in over $80 \%$ within approximately 3 years $(2,3)$. This suggests that 3 Y-RFS is more useful than 5Y-RFS for evaluation of the effect of adjuvant therapy given within approximately 6 months postoperatively. In the present study, 3Y-RFS was equivalent or similar to 5Y-RFS in stage IIIa, stage IIIb, and overall stage III, suggesting that therapeutic efficacy can be accurately reflected by early analysis after a shorter follow-up period.

There have been many reports on the close relationship between the detection of cytokeratin positive occult neoplastic cells (ONCs) freely floating in the sinuses of lymph node distant from the primary tumor and the metastasis/ recurrence of cancer (9-12). ONCs are malignant cells that can be easily detected by immunostaining when trapped in the lymph node sinuses $(9,10)$. These cells are observed in more than $80 \%$ of patients with recurrent stage II/III cancer, and ONC clusters about $0.2 \mathrm{~mm}$ in diameter ( $\leq 10 \mathrm{ONCs}$ ) or malignant micro-aggregates $(>10$ ONCs) are also found in patients with stage III cancer and nodal metastases. ONC clusters have been reported to differ from isolated tumor cells $(\leq 0.2 \mathrm{~mm})$ or micrometastases $(0.2 \mathrm{~mm}<\mathrm{MM} \leq 2 \mathrm{~mm})$ anchored in the lymph nodes and may be higher-grade occult systemic metastases than such isolated tumor cells or micrometastases $(11,12)$. The most important task of postoperative adjuvant chemotherapy may be the eradication of such circulating clusters and micro-aggregates of cancer cells, which appear in the perioperative period (10-12). To achieve a true survival benefit, improvement of the survival rate after recurrence has been reported to be of the utmost importance $(27,28)$. The selection of an appropriate regimen for the perioperative period is required at the time before distant metastasis/recurrence has occurred, especially in patients with a high risk of distant metastasis/recurrence due to the presence of ONC clusters or micro-aggregates (18-20). In order to avoid the use of chemotherapy that is too weak, it is desirable for adjuvant therapy to include the standard drug (5-FU) plus other active drugs. According to the results of the present study, stage IIIb (TNM stage IIIC) patients in the FL group showed more satisfactory results in all analyses than patients in the FLC group, although there were no significant differences between the two groups. Further studies are needed to ascertain whether stage IIIb patients with advanced cancer should receive tumor dormancy therapy and/or best supportive care that attaches greater importance to QOL rather than powerful postoperative chemotherapy $(29,30)$. A detailed evaluation of the control of tumor proliferation needs to be done in a larger number of stage IIIb patients.

\section{Acknowledgements}

This study was supported by grants from the Occult Neoplastic Cells Research and Study Group (no. 2009-5007; Tokai University Hachioji Hospital, Hachioji, Tokyo, Japan) and the Research and Study Program of Tokai University Educational System General Research Organization (no. 2007-04; Tokai University Hospital, Isehara, Kanagawa, Japan).

\section{References}

1. Multi-Institutional Registry of Large Bowel Cancer in Japan, vol. 23, Cases treated in 1994. Japanese Society for Cancer of the Colon and Rectum, Tokyo, 2002.

2. Makuuchi M and Sugihara K: Knacks \& Pitfalls: Surgery of the Colon, Rectum and Anus (2nd edition). Bunkoudou Co., Ltd., Tokyo, 2004.

3. Guideline for Large Bowel Cancer in Japan. Japanese Society for Cancer of the Colon and Rectum, Tokyo, 2005.

4. TNM classification of malignant tumours (6th edition), John Wiley \& Sons, Inc., New York, 2002.

5. General Rules for Clinical and Pathological Studies on Cancer of the Colon, Rectum and Anus. Japanese Society for Cancer of the Colon and Rectum (7th Edition). Kanehara \& Co., Ltd., Tokyo, 2006

6. National Institutes of Health Consensus Development Panel. National Institutes of Health consensus development conference statement: adjuvant therapy for breast cancer, November 1-3, 2000. J Natl Cancer Inst 93: 979-989, 2001.

7. Goldhirsch A, Glick JH, Gelber RD, Coates AS and Senn HJ: Meeting highlights: international consensus panel on the treatment of primary breast cancer. J Clin Oncol 19: 3817-3827, 2001.

8. Abrams JS: Adjuvant therapy for breast cancer-results from the USA consensus conference. Breast Cancer 8: 298-304, 2001.

9. Mukai M: Occult neoplastic cells and malignant micro-aggregates in lymph node sinuses: review and hypothesis. Oncol Rep 14: 173-175, 2005.

10. Mukai M, Sato S, Tajima T, Kimura T, Komatsu N, Ninomiya H, Nakasaki H, Ogoshi K and Makuuchi H: Predicting recurrence and metastasis of stage III/Dukes' C colorectal cancer with lymph node metastasis. Oncol Rep 12: 1301-1304, 2004.

11. Mukai M, Sato S, Ninomiya H, Wakui K, Tsuchiya K, Komatsu N, Nakasaki H and Makuuchi M: Recurrence and 5-FU sensitivity of stage III/Dukes' C colorectal cancer with occult neoplastic cells in lymph node sinuses. Oncol Rep 14: 1165-1169, 2005.

12. Mukai M, Sato S, Ninomiya H, Wakui K, Komatsu N, Matsui N, Nakamura M, Nakasaki $\mathrm{H}$ and Makuuchi $\mathrm{H}$ : Sensitivity to CPT-11 and platinum derivatives for stage III/Dukes' C colorectal cancer with occult neoplastic cells in lymph node sinuses. Oncol Rep 17: 1027-1032, 2007.

13. Douillard JY, Cunningham D, Roth AD, Navarro M, James RD, Karasek P, Jandic P, Iveson T, Carmichael J, Alaki M, Gruia G, Awad L and Rougier P: Irinotecan combined with fluorouracil compared with fluorouracil alone as first-line treatment for metastatic colorectal cancer: A multicentre randomized trial. Lancet 355: 1041-1047, 2000.

14. Saltz LB, Cox JV, Blanke C, Rosen LS, Fehrenbacher L, Moore MJ, Maroun JA, Ackland SP, Locker PK, Pirotta N, Elfring GL and Miller L, for the Irinotecan study group: Irinotecan plus fluorouracil and leucovorin for metastatic colorectal cancer. N Engl J Med 343: 905-914, 2000.

15. Tournigand C, Achille TAE, Lledo G, Flesh M, Quinaux DM-ME, Couteau C, Buyse M, Ganem G, Landi B, Colin P, Louvet C and De Gramont A: FOLFIRI followed by FOLFOX 6 or the reverse sequence in advanced colorectal cancer: a randomized GERCOR study. J Clin Oncol 22: 229-237, 2004.

16. Colucci G, Gebbia V, Paoletti G, Giuliani F, Caruso M, Gebbia N, Cartení G, Agostara B, Pezzella G, Manzione L, Borsellino N, Misino A, Romito S, Durini E, Cordio S, Seri MD, Lopez M and Maiello E: Phase III randomized trial of FOLFIRI versus FOLFOX 4 in the treatment of advanced colorectal cancer: a multicenter study of Gruppo Oncologico Dell'Italia Meridionale. J Clin Oncol 23: 4866-4875, 2005. 
17. Machover D, Schwarzenberg L, Goldschmidt E, Tourani JM, Michalski B, Hayat M, Dorval T, Misset JL, Jasmin C, Maral R and Mathe G: Treatment of advanced colorectal and gastric adenocarcinomas with 5-FU combined with high-dose folinic acid: a pilot study. Cancer Treat Rep 66: 1803-1807, 1982.

18. Ito I, Mukai M, Ninomiya H, Kishima K, Tsuchiya K, Tajima T, Oida Y, Nakamura M and Makuuchi H: Comparison between intravenous and oral postoperative adjuvant immunochemotherapy in patients with stage II colorectal cancer. Oncol Rep 20: 1189-1194, 2008.

19. Ito I, Mukai M, Ninomiya H, Kishima K, Tsuchiya K, Tajima T, Oida Y, Nakamura M and Makuuchi H: Comparison between intravenous and oral postoperative adjuvant immunochemotherapy in patients with stage III colorectal cancer. Oncol Rep 20: 1521-1526, 2008

20. Mukai M, Kishima K, Uchiumi F, Ishibashi E, Tajima T, Fukasawa M, Nakamura M and Makuuchi M: Comparison of QOL and adverse events for postoperative adjuvant chemotherapy in outpatients with node-positive colorectal cancer or gastric cancer. Oncol Rep 21: 1061-1066, 2009.

21. Wolmark N, Rockette H, Fisher B, Wickerham DL, Redmond C, Fisher ER, Jones J, Mamounas EP, Ore L, Petrelli NJ, Spurr CL, Dimitrov N, Romond EH, Sutherland CM, Kardinal CG, DeFusco PA and Jochimsen P: The benefit of leukovorinmodurated fluorouracil as post operative adjuvant therapy for primary colon cancer: results from National Surgical Adjuvant Breast and Bowel Project Protocol C-03. J Clin Oncol 11: 1879-1887, 1993.

22. Duschinsky R, Pleven E and Heidelberger C: The synthesis of 5-fluoropyrimidines. J Am Chem Soc 79: 4559-4560, 1957.

23. Heidelberger C, Leibman KC, Harbers E and Bhargava PM: The comparative utilization of uracil-2-c14 by liver, intestinal mucosa and Flexner-jobling carcinoma in the rat. Cancer Res 17: 399-404, 1957
24. Berger SH and Hakala MT: Relationship of dUMP and free FdUMP pools to inhibition of thymidylate synthase by 5 fluorouracil. Mol Pharmacol 25: 303-309, 1984.

25. Lokich JJ, Ahlgren JD, Gullo JJ, Philips JA and Fryer JG: A prospective randomized comparison of continuous infusion of fluorouracil with a conventional bolus schedule in metastatic colorectal carcinoma: a mid-Atlantic Oncology Program study. J Clin Oncol 17: 425-432, 1989.

26. De Gramont A, Bosset JF, Milan C, Rougier P, Bouché O, Etienne PL, Morvan F, Louvet C, Guillot T, François E and Bedenne L: Randomized trial comparing monthly low dose leucovorin and fluorouracil bolus with bimonthly high-dose leucovorin and fluorouracil bolus plus continuous infusion for advanced colorectal cancer. J Clin Oncol 15: 808-815, 1997.

27. Feinstein AR, Sosin DM and Wells CK: The Will Rogers phenomenon: stage migration and new techniques as a source of misleading statistics for survival in cancer. N Engl J Med 312: 1604-1608, 1985.

28. Bunt AMG, Hermans J, Smit VTHBM, van de Velde CJH, Fleuren GL and Bruijn JA: Surgical/pathologic stage migration confounds comparisons of gastric cancer survival rates between Japan and Western countries. J Clin Oncol 13: 19-25, 1995.

29. Scheithauer W, Rosen H, Kornek GV, Sebesta C and Depisch D: Randomised comparison of combination chemotherapy plus supportive care with supportive care alone in patients with matastatic colorectal cancer. Br Med J 306: 752-755, 1993.

30. Takahashi Y and Nishioka K: Survival without tumor shrinkage: re-evaluation of survival gain by cytostatic effect of chemotherapy. J Natl Cancer Inst 87: 1262-1263, 1995. 